\title{
Evaluation of Differences in Softening of Apple Genotypes by Linear Regression
}

\author{
Hiroshi Iwanami, Makoto Ishiguro, ${ }^{1}$ Nobuhiro Kotoda, Sae Takahashi, \\ and Junichi Soejima ${ }^{2}$ \\ Department of Apple Research, National Institute of Fruit Tree Science, \\ Morioka 020-0123, Japan
}

Additional index words. Malus $\times$ domestica, breeding

\begin{abstract}
The firmness of the flesh in 27 apple (Malus $\times$ domestica Borkh.) cultivars and selections (genotypes) was measured as an indicator of storage potential at 20 days after harvest under $20 \pm 2{ }^{\circ} \mathrm{C}, 80 \% \pm 5 \%$ relative humidity storage conditions. Softening ranged from $9 \%$ to $58 \%$ of initial values among genotypes after 20 days of storage. In some genotypes, softening was not continuous, a minimum firmness being reached before day 20. After a period of rapid softening, firmness declined to at least $20 \%$ of that at harvest. For each genotype, linear regression analysis of firmness changes from harvest until when firmness decreased by $20 \%$ was carried out. In genotypes in which firmness did not drop $\mathbf{2 0 \%}$ within 20 days of storage, the entire dates to 20 days were used for analysis. The homogeneity of the regression residual variances and their normal distribution was not rejected at $\boldsymbol{P}=\mathbf{0 . 0 5}$, and the linear regression analysis was assumed to be applicable to the change in firmness for each genotype. Results of the regression analysis showed that the regression was significant for all genotypes except one. Therefore, storage potential could be evaluated by comparing the regression coefficient of each genotype.
\end{abstract}

Texture, particularly firmness, is often used as an indicator of maturity, ripeness, and quality of apples (Abbott, 1994). Many studies have used changes in firmness during storage to investigate different ripening types and the effects of storage technologies (Drake, 1993; Gussman et al., 1993; Ingle and D'Souza, 1989; Plotto et al., 1995, 1997; Tong et al., 1999; Watkins et al., 2000). Moreover, several studies have predicted changes in fruit firmness from that at harvest time to after or during storage using regression equations by measuring quality at harvest (Blankenship et al., 1997; Evensen et al., 1993; Ingle and Morris, 1989; Ingle et al., 2000; Johnson and Ridout, 1998). However, these studies used only one or a few commercially important cultivars and the data were not used to compare cultivar-related differences in softening rates during storage.

Many fruit are needed to evaluate storage potential of apple cultivars and selections. However, in breeding programs, young seedlings usually do not bear enough fruit to permit extensive sampling for storage tests, and as a consequence, this important part of the seedling screening is ignored in many apple-breeding programs (Alston, 1988).

The objective of this study was to develop a method to evaluate changes in fruit firmness that could be used as an indicator of storage potential, using restricted fruit samples from apple breeding programs.

Received for publication 7 May 2003. Accepted for publication 31 Dec. 2003.

${ }^{1}$ Current address: Yamagata Prefectural Horticultural Experiment Station, Sagae, Yamagata 991-0043.

${ }^{2}$ Current address: National Institute of Fruit Tree Science, Fujimoto, Tsukuba, Ibaraki 305-8605.

\section{Materials and Methods}

Fruit materials. Twenty-seven apple cultivars and selections from the orchards at the Apple Research Center, National Institute of Fruit Tree Science (NIFTS) in Japan were selected based on the diversity of harvest date, rootstock, and years since planting/grafting (Table 1). The genotypes consist of 16 cultivars that originated in Japan and have been used as parents in breeding, six cultivars originating from North America, and five promising selections from the NIFTS apple-breeding programs. Twenty-five fruit samples from each cultivar and selection were picked randomly from a tree when most of the fruit was judged to be mature based on sensory evaluations from August to November 2001. Fruit of similar size (within $15 \%$ of average fruit weight) was picked from each cultivar/selection because fruit size affects fruit firmness (Blankenship, 1997) and a strong relationship has been shown to exist between fruit size and fruit firmness after storage (Marmo et al., 1985).

Storage conditions. Five fruit from each sample of the 27 cultivars or selections were used for measurement of firmness at harvest. The remaining 20 fruit were stored in $25-\mathrm{L}$ containers, which were arranged on racks, in a chamber controlled at $20 \pm 2{ }^{\circ} \mathrm{C}, 80 \%$ $\pm 5 \%$ relative humidity $(\mathrm{RH})$ with constant air circulation. Firmness of four to five fruit was measured at 5-d intervals until $20 \mathrm{~d}$ after harvest. Fruit displaying rot were immediately removed from the containers during storage.

Firmness measurement. A fruit pressure tester (FT327; McCormick Fruit Technology, Wash.), mounted in a drill press, and fitted with an 11.1-mm probe, was used on the pared surfaces of the sunny and shady sides of each fruit. Data were expressed as Newtons (N).

Statistical analysis. Firmness measurements of each cultivar/selection (genotype) were subjected to linear regression analysis and to analysis of variance (ANOVA). Individual fruit data for each sampling, not mean value of each sampling fruit, and only the reduction periods in firmness of $20 \mathrm{~d}$ of storage were used for the analyses. The model of ANOVA was yijk $=\mu+$ gi + bi $x+$ eijk, where yijk is the firmness measurement as the dependent variable of the kth fruit at jth days after harvest of the ith genotype, $\mu$ is the overall mean, gi is a random effect contributed by the ith genotype, bi is the regression coefficient of the ith genotype, $x$ is the kth fruit of ith genotype $j$ th days after harvest, and eijk is the residual of the regression line of the kth fruit of jth days after harvest of the ith genotype. ANOVA was performed using a Statistical Analysis System (SAS Institute, Cary, N.C.).

\section{Results and Discussion}

Firmness of the flesh at harvest and the percentage firmness reduction after $20 \mathrm{~d}$ of storage varied among genotypes (Table 2). Softening ranged from $9 \%$ to $58 \%$ of initial firmness values. 'Red Gold,' 'Starking Delicious' and 'Orin' had relatively firmer fruit at harvest (77.7, 72.2, and 74.5 N, respectively), but fruit became very soft, after $20 \mathrm{~d}$ of storage (40.5, 33.9, and 40.9 N, respectively). In contrast, 'Santaro' and 'Toko' had relatively soft fruit at harvest $(59.8 \mathrm{~N})$, but their fruit were firmer after $20 \mathrm{~d}$ of storage (42.7 and 46.1 N respectively) than those of 'Red Gold,' 'Starking Delicious' and 'Orin.'

Fruit did not always soften continuously during storage. The flesh of some genotypes softened rapidly and by at least $20 \%$ of harvest firmness until $10 \mathrm{~d}$ after harvest but then softened slowly day 10 to 20 (Fig. 1B). The minimum firmness of 'Tsugaru' was $52.2 \mathrm{~N}$ (27\% loss of harvest firmness), was much higher than that of 'Red Gold,' which was $40.5 \mathrm{~N}$ ( $48 \%$ loss of harvest firmness). These results are consistent with those of Johnston et al. (2002) who suggested that apples only soften by $25 \%$ to $50 \%$ to a final firmness of 35 to $50 \mathrm{~N}$. On the other hand, some genotypes continued to soften for $20 \mathrm{~d}$. Firmness of 'Megumi' and 'Starking Delicious' declined to $31.9 \mathrm{~N}$ (49\% loss) and $33.9 \mathrm{~N}$ (53\% loss) on day 20, respectively (Fig. 1A), in contrast to that of 'Fuji' and 'Kitaro,' which was $67.5 \mathrm{~N}$ (13\% loss) and $62.9 \mathrm{~N}$ (13\% loss), respectively at this time (Fig. 1D).

The reduction in firmness in 'Tsugaru' $(27 \%)$ and 'Kinsei' (22\%) was similar on day 20 , but different on day 10 , being, $27 \%$ and $6 \%$, respectively (Fig. 1B and D). In contrast, the reduction in firmness of 'Kitaro' was 7\% on day 10 and almost identical to that of 'Kinsei,' but that of 'Kitaro' on day $20(13 \%)$ and less than that of 'Kinsei' (22\%) (Fig. 1D). Therefore, the extent of softening after harvest is greatly influenced by the storage period, and the genotypic differences in the storage potential cannot be evaluated by total changes in firmness over a single ripening period. However, determining 

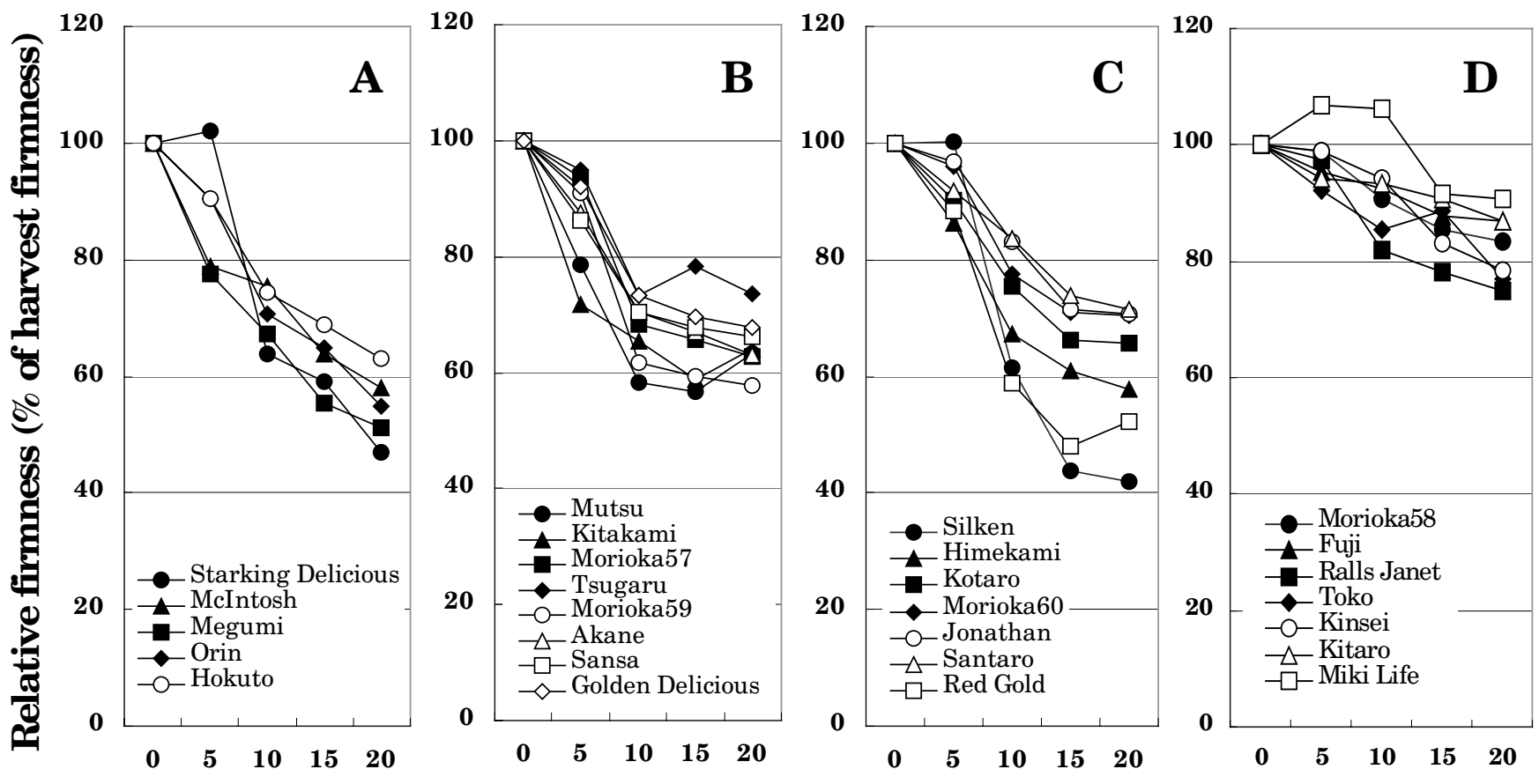

\section{Storage duration (day)}

Fig. 1 Relative flesh firmness of 27 apple cultivars and selections during $20 \pm 2{ }^{\circ} \mathrm{C}, 80 \% \pm 5 \% \mathrm{RH}$ storage. The relative firmness was calculated as the average firmness of four or five fruit of each sampling compared with the average harvest firmness of five fruit of each genotype. Flesh firmness (A) decreased rapidly and constantly during $20 \mathrm{~d}$; (B) decreased rapidly during $10 \mathrm{~d}$ and changed little from 10 to $20 \mathrm{~d}$; (C) decreased during $15 \mathrm{~d}$ and changed little from 15 to 20 $\mathrm{d}$; (D) decreased gradually during $20 \mathrm{~d}$.

how long it takes for fruit to become too soft for market acceptance requires regular evaluation until firmness reaches a certain value. For this purpose, many samples of fruit are needed when a genotype is likely to have long storage capability. In this study, the firmness of 'Miki Life' decreased only $9 \%$ by day 20 , and more fruit would be needed to continue measuring firmness (Fig. 1D).

Since it is unnecessary for evaluating storage potential to observe changes in firmness after a minimum value has been reached, a linear regression of firmness against a specified loss of firmness ( $20 \%$ of harvest values) was applied. When firmness did not decrease $>20 \%$ within $20 \mathrm{~d}$ of storage, the full length of storage was used for linear regression analysis. Homogeneity of the variances of the regression residuals among sampling dates for each genotype was tested by Bartlett's test, and the normal distribution of the residual was tested using the Kolmogorov-Smirnov one-sample test. The results of these tests showed that the homogeneity of the variance and normal distribution was not rejected at $P=0.05$, and therefore, linear regression analysis was assumed to be applicable to this data.

Regressions were significant $(P<0.05)$ for all genotypes except one (Table 2 ). This result indicated that the regression coefficient (b), which is the firmness reduction rate and its standard error, could be calculated within at least $20 \mathrm{~d}$ of harvest and that the regression coefficient could be compared among genotypes.

Johnston et al. (2002) reported that the reduction in firmness in many apple cultivars can be characterized by a nonlinear curve consisting of three distinct phases; i.e., fruit softening slowly in the first phase (I), more rapidly in the second phase (II), and slowly in the final phase (III). Johnston et al. (2001), moreover, used a nonlinear regression model with three parameters to describe the change in firmness during storage.

In our studies, the regression residual vari- ability could be divided into two components: within-sampling variability and deviation from linearity. If the relationship between the firmness and length of storage is a straight line, then the deviation-from-linearity MS and the within-sampling MS will be estimates of the same variance. Thus, the F value for the fitness for a straight line was calculated as $\mathrm{F}$

Table 1. Twenty-seven apple cultivars and selections and tree age, rootstock, and harvest date evaluated in this study.

\begin{tabular}{lcll}
\hline Cultivar or selection & Tree age $^{\mathrm{z}}$ & Rootstock & Harvest date \\
\hline Kitakami & $(3)$ & Jonathan/Marubakaido & 31 Aug. \\
Sansa & 15 & M26E & 7 Sept. \\
Tsugaru & 7 & JM7 & 14 Sept. \\
Akane & $(3)$ & Jonathan/Marubakaido & 14 Sept. \\
Miki Life & 9 & M9 & 14 Sept. \\
McIntosh & 41 & Marubakaido & 20 Sept. \\
Silken & 11 & M9 & 20 Sept. \\
Himekami & $(17)$ & Starking Delicious/MM106 & 20 Sept. \\
Santaro & 12 & M26 & 28 Sept. \\
Red Gold & 7 & M9 & 5 Oct. \\
Morioka57 & 12 & M26 & 5 Oct. \\
Morioka59 & 10 & M9 & 5 Oct. \\
Morioka60 & 10 & M9 & 11 Oct. \\
Jonathan & 43 & Marubakaido & 11 Oct. \\
Kitaro & 10 & JM2 & 11 Oct. \\
Starking Delicious & 7 & JM7 & 20 Oct. \\
Kotaro & 11 & JM2 & 26 Oct. \\
Hokuto & 7 & JM7 & 26 Oct. \\
Golden Delicious & 7 & M9 & 26 Oct. \\
Mutsu & 7 & JM7 & 26 Oct. \\
Orin & 7 & M9 & 2 Nov. \\
Morioka58 & 11 & M9 & 2 Nov. \\
Megumi & Unknown & 9 Nov. \\
Kinsei & CG57 & 9 Nov. \\
Fuji & 75 & M9 & 9 Nov. \\
Ralls Janet & 7 & M9 & 17 Nov. \\
Toko & 15 & CG57 & 17 Nov. \\
\hline Thown & 7 &
\end{tabular}

${ }^{2}$ Numeral in parenthesis indicates years since top-grafting on intermediate stock. 
= the deviation-from-linearity MS divided by within-sampling MS and tested by the F test. The $\mathrm{F}$ test for the fitness for a straight line showed that the linearity was not rejected in genotypes in which firmness decreased gradually, i.e., those in which firmness decreased $20 \%$ at $15 \mathrm{~d}$ or more than $20 \mathrm{~d}$ (Table 3 ). Johnston et al. (2001) also observed that the rapid-phase of softening (phase II) was not apparent at storage temperatures of 20 and 30 ${ }^{\circ} \mathrm{C}$ in some slow-softening cultivars and they could not fit the nonlinear regression model they proposed to the curves for the firmness reduction of the cultivars. In our studies, when firmness measurements continued for $40 \mathrm{~d}$ after harvest in some genotypes in which firmness decreased gradually, the phase changes were not observed (data not shown).

In genotypes in which firmness decreased $20 \%$ by day 10 , the deviation-from-linearity MS was significantly large (143.6) (Table 3). These genotypes appeared to have distinct phase changes from phase I to phase II. 'Starking Delicious' and 'Silken' were the genotypes in which firmness decreased $20 \%$ by day 10 and the firmness of the cultivars changed little within $5 \mathrm{~d}$ of harvest and decreased rapidly within 5 to $10 \mathrm{~d}$ of harvest (Fig. $1 \mathrm{~A}$ and C). The regression residual variances ( $\mathrm{Ve}$ ) of the cultivars were large (84.08 and 52.96, respectively) (Table 2). However, linear regression analysis was also applicable to these genotypes having distinct phase change because the variances in firmness of individual fruit within sampling were relatively large and the regression residuals were not significantly imbalanced from the regression line.

When linear regression equations were calculated for two sets of sampling, i.e., when firmness decreased $20 \%$ at $5 \mathrm{~d}$, the Ve indicates the firmness variance for each sampling time. The firmness of 'McIntosh' did not decrease $(P$ $=0.076)$ because of the large residual variance $(\mathrm{Ve}=91.8)$, although the average firmness rapidly decreased during the first $5 \mathrm{~d}$ after harvest. The large Ve of 'McIntosh' resulted from the large variances in firmness at each sampling point.
The average firmness of 'Miki Life' was higher than that at harvest for $10 \mathrm{~d}$, and it then began to decrease for the next $15 \mathrm{~d}$. The firmness variance within sampling was also large in the cultivar (data not shown). Therefore, the large Ve of the cultivar resulted from the combined effect of the large residual from the regression line and the large firmness variances within the sampling.

In breeding situations, many cultivars and seedlings are needed to effectively evaluate storage potential and select superior genotypes. Alston (1988) evaluated the storage potential in many cultivars and seedlings in his applebreeding program. However, he evaluated the storage potential by measuring firmness at only one time after storage. Although the curves showing the reductions in firmness were not always linear, linear regression analysis is still very effective for evaluating storage potential because the regression was significant for at least $20 \mathrm{~d}$ after harvest in almost all genotypes under the conditions used in this study; furthermore, regression analysis could be adapted

Table 2. Flesh firmness changes during 20-d storage and results of linear regression analysis on the firmness during storage of each of the 27 cultivars and selections.

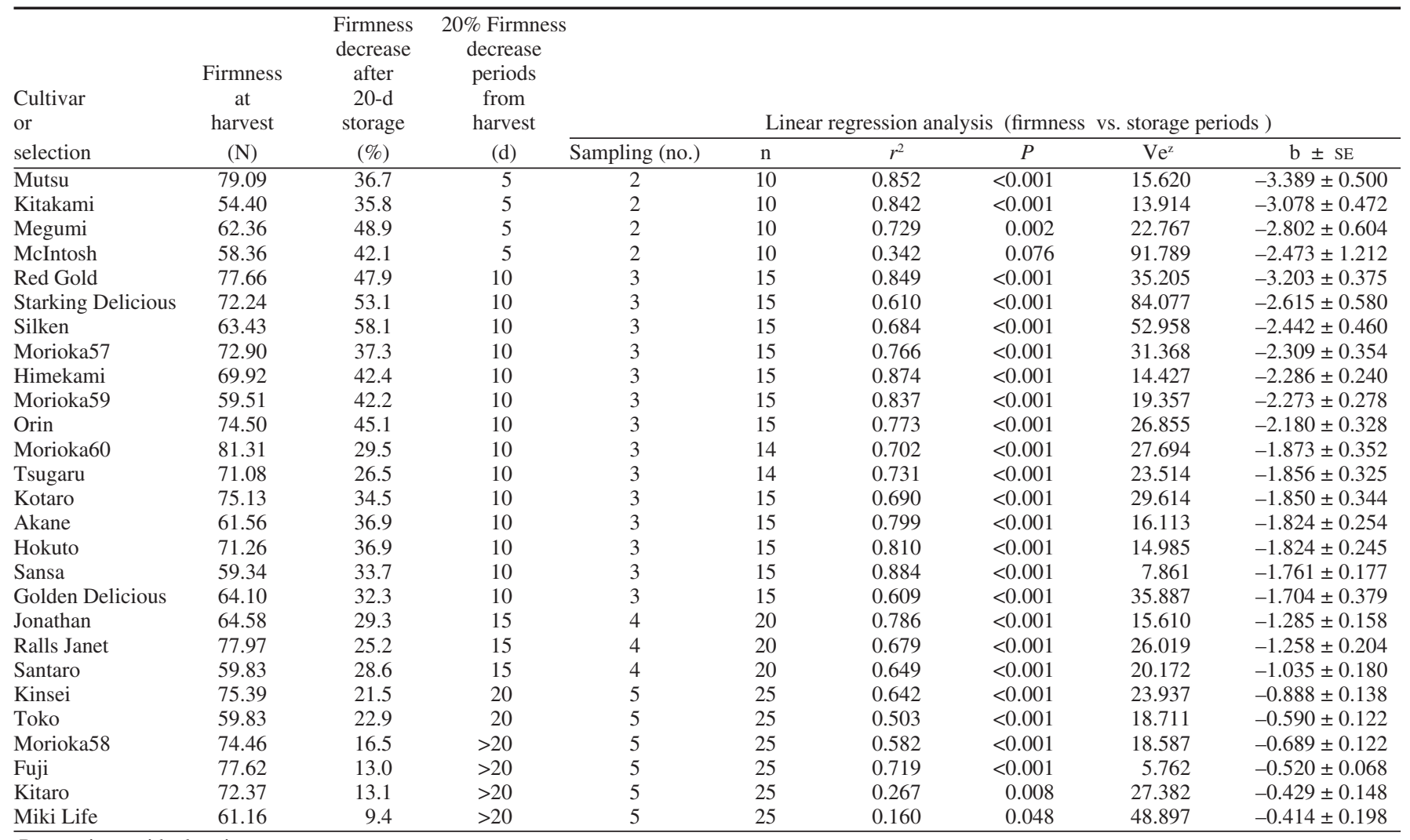

${ }^{2}$ Regression residual variance

Table 3. Analysis of variance for firmness and mean square and significances of linear regression in all studied genotypes except 'McIntosh' and in three groups divided according to firmness decrease periods.

\begin{tabular}{|c|c|c|c|c|c|c|c|c|}
\hline \multirow[b]{3}{*}{ Source of variation } & \multirow{2}{*}{\multicolumn{2}{|c|}{ Included all genotypes }} & \multicolumn{6}{|c|}{$\begin{array}{l}\text { Genotypes in which the firmness } \\
\text { decreased } 20 \% \text { of harvest firmness at }\end{array}$} \\
\hline & & & \multicolumn{2}{|c|}{$10 \mathrm{~d}$} & \multicolumn{2}{|c|}{$15 \mathrm{~d}$} & \multicolumn{2}{|c|}{$>20 \mathrm{~d}$} \\
\hline & df & Mean squares & $\mathrm{df}$ & Mean squares & $\mathrm{df}$ & $\overline{\text { Mean squares }}$ & $\mathrm{df}$ & $\overline{\text { Mean squares }}$ \\
\hline Cultivar or selection (genotype) & 25 & $937.42^{* *}$ & 13 & $660.99^{* *}$ & 2 & $1644.27^{* * *}$ & 5 & $1194.79^{* *}$ \\
\hline Linear regression & 26 & $913.24^{* *}$ & 14 & $1175.34^{* *}$ & 3 & $897.29^{* *}$ & 6 & $466.09^{* *}$ \\
\hline Residual & 396 & 25.84 & 180 & 30.04 & 54 & 20.60 & 138 & 23.88 \\
\hline Deviation from linearity & 38 & $68.44^{* *}$ & 14 & $143.60^{* *}$ & 6 & $24.84^{\mathrm{NS}}$ & 18 & $24.52^{\mathrm{NS}}$ \\
\hline Within sampling & 358 & 21.32 & 166 & 20.47 & 48 & 20.07 & 120 & 23.78 \\
\hline
\end{tabular}

ss.** Nonsignificant and significant at $P<0.01$, respectively, using F test. 
to genotypes in which reductions in firmness occurred either rapidly or gradually in the same way. As a consequence, superior genotypes can be selected to compare the regression coefficients of seedlings with those of control cultivars. When the nonlinear regression model that was proposed by Johnston et al. (2001) is applied to softening curve during storage, genotypic differences can be also evaluated to compare the rate of firmness change per day, which is one of the parameters in the model. The nonlinear regression model, however, requires three parameters to fit the softening curve, and one of those parameters is a final firmness asymptote. Therefore, firmness must be measured until it no longer decreases if the nonlinear model is to be used. Since the yield of young seedlings is limited, their fruit are not very appropriate for use in storage potential evaluations. In this study, 25 fruit were harvested, and five were used to determine firmness at $5 \mathrm{~d}$ intervals. Measurements of firmness continued from harvest until the average firmness decreased $20 \%$ of harvest firmness or until $20 \mathrm{~d}$ had elapsed.

Ingle and Morris (1989) observed that there were good correlations between firmness changes at 20 and that at $0{ }^{\circ} \mathrm{C}$ in 'Rome' apple. However, Johnston et al (2001) observed that rapid softening of some genotypes occurred only when the fruit had been stored at cold temperature. Further studies are required to determine the genotypic differences of softening responses to the storage temperature.

\section{Literature Cited}

Abbott, J.A. 1994. Firmness measurement of freshly harvested 'Delicious' apples by sensory methods, sonic transmission, magness-taylor, and compression. J. Amer. Soc. Hort. Sci. 119:510-515

Alston, F.H. 1988. Breeding apples for long storage. Acta Hort. 224:109-117.

Blankenship, S.M., M. Parker, and C.R. Unrath. 1997. Use of maturity indices for predicting poststorage firmness of 'Fuji' apples. HortScience 32:909-910.

Drake, S.R. 1993. Short-term controlled atmosphere storage improved quality of several apple cultivars. J. Amer. Soc. Hort. Sci. 118:486-489.

Evensen, K., P. Hammer, R. Crassweller, G. Greene, and L. Lehman-Salada. 1993. Predicting firmness of 'York Imperial' apples after long-term storage. HortTechnology 3:318-322.

Gussman, C.D., J.C. Goffreda, and T.J. Gianfagna. 1993. Ethylene production and fruit-softening rates in several apple fruit ripening variants. HortScience 28:135-137.

Ingle, M. and J.C. Morris. 1989. Predicting firmness changes of 'Rome' apples in refrigerated storage. J. Amer. Soc. Hort. Sci. 114:90-94

Ingle, M. and M.C. D’Souza. 1989. Fruit characteristics of 'Red Delicious' apple strains during maturation and storage. J. Amer. Soc. Hort. Sci. 114:776-780.

Ingle, M., M.C. D'Souza, and E.C. Townsend. 2000. Fruit characteristics of 'York' apples during development and after storage. HortScience 35:95-98.

Johnson, D.S. and M.S. Ridout. 1998. Prediction of storage quality of 'Cox's Orange Pippin' apples from nutritional and meteorological data using multiple regression models selected by cross validation. J. Hort. Sci. Biotechnol. 73:622-630
Johnston, J.W., E.W. Hewett, M.L.A.T.M. Hertog, and F.R. Harker. 2001. Temperature induces differential softening responses in apple cultivars. Postharvest Biol. Technol. 23;185-196.

Johnston, J.W., E.W. Hewett, and M.L.A.T.M. Hertog. 2002. Postharvest softening of apple (Malus domestica) fruit: A review. N.Z. J. Crop Hort. Sci. 30:145-160.

Marmo, C. A., W. J. Bramlage, and S. A. Weis. 1985. Effects of fruit maturity, size, and mineral concentration on predicting the storage life of 'McIntosh' apples. J. Amer. Soc. Hort. Sci. 110:499-502.

Plotto, A., A.N. Azarenko, J.P. Mattheis, and M.R. McDaniel. 1995. 'Gala', 'Braeburn', and 'Fuji' apples: Maturity indices and quality after storage. Fruit Var. J. 49:133-142.

Plotto, A., A.N. Azarenko, M.R. McDaniel, P.W. Crockett, and J.P. Mattheis. 1997. Eating quality of 'Gala' and 'Fuji' apples from multiple harvests and storage durations. HortScience 32:903-908.

SAS Institute. 1989. SAS user's guide. SAS Inst., Cary, N.C.

Tong, C., D. Krueger, Z. Vickers, D. Bedford, J. Luby, A. El-Shiekh, K. Shackel, and H. Ahmadi. 1999. Comparison of softening-related changes during storage of 'Honeycrisp' apple, its parent, and 'Delicious'. J. Amer. Soc. Hort. Sci. 124:407-415.

Watkins, C.B., A. Leake, and J.H. Bowen. 1995 Maturation and storage quality of six 'Golden Delicious' x 'Red Dougherty' apple selections. N.Z. J. Crop Hort. Sci. 23:49-54.

Watkins, C.B., J.F. Nock, and D. Whitaker. 2000. Responses of early, mid and late season apple cultivars to postharvest application of 1-methylcyclopropene (1-MCP) under air and controlled atmosphere storage conditions. Postharvest Biol. Technol. 19:17-32. 